\title{
Synergistic effect of Carbon-monoxide, Noise, Smoking and Hypertension on Hearing of Steel Industry workers
}

\author{
Pragnya Prusty*, Kaibalyabala Mohanty and Subhasmita Sahoo \\ Institute of Health Sciences, Bhubaneswar, India
}

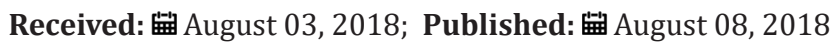

*Corresponding author: Pragnya Prusty, Institute of Health Sciences, Bhubaneswar, India

\begin{abstract}
The synergistic effect of Carbon-monoxide, Noise, Smoking and Hypertension on Hearing of Steel Industry workers in Odisha has been examined in the present study. The objectives of the present study were to assess the auditory effects of the combined exposure of CO, Noise, Impact of smoking and Hypertension. 72 male workers (smokers and non-smokers) from the steel industry were examined, among which 62 were exposed to noise and CO (CEG- Continuously Exposed Group) simultaneously and 10 workers exposed to only noise (IEG-Intermittently Exposed Group). Biological concentrations of CO in blood (COHb), hypertension was measured considering smoking habits, the type of exposure ( $\mathrm{CO}$ and noise or noise only), the time of exposure, the level of noise \& age and audiometric tests were done to assess hearing ability. It has been observed that the noise levels measured in SMS, RMS, MBF s \&Power plant sections is more than PEL i.e. 8 hours, TWA 90 dBA specified in the state regulations. Workers were not using ear protection devices. Study indicate the prevalence of hearing impairment was significantly more in CEG (85.14\%) as compared to IEG $(14.81 \%)$. The noise exposure and hearing impairment was found to be significant $(\mathrm{p}<0.05)$. Positive relation was found among the level of noise, CO, Smoking \& Hypertension $(p<0.05)$. The results of present study indicate that hypertension \& hearing impairment are common problem among workers exposed to high levels of occupational noise.
\end{abstract}

Keywords: Synergistic effect; Carbon-monoxide; Hypertension; NIHL; Steel industry

Abbreviations: TTS: Temporary Threshold Shift; NIHL: Noise Induced Hearing Loss; SMG: Steel Melting Section; RMS: Rolling Mill Section; IEG: Intermittently Exposed Group

\section{Introduction}

Noise is any unwanted sound judged to be unpleasant loud or disruptive to hearing affecting health in today's world [1]. Exposure to continuous noise at a level higher than $90 \mathrm{dBA}$ for 8 hours may lead to Noise Induced Hearing Loss (NIHL). It is estimated worldwide $16 \%$ hearing disability is caused by occupational noise exposure. Steel plant is considered as one of the noisiest industries in manufacturing sectors. In India, the prevalence of hypertension was found to be $25.51 \%$ among workers exposed to high level of noise [2]. There are several factors that can make the hearing worse such as smoking, noise, vibrations, and environmental chemical contaminants(solvents), metals, asphyxiants etc. Among chemical contaminants, CO deserves special attention (Graph 1).

CO is a colorless, odourless and tasteless gas that combines with hemoglobin to produce carboxyhemoglobin, which usurps the space in hemoglobin that normally carries oxygen but is ineffective for delivering oxygen to bodily tissues. Concentrations as low as $667 \mathrm{ppm}$ may cause up to $50 \%$ of the bodies haemoglobin to convert to carboxyhemoglobin. A level of 50\% carboxyhemoglobin may result in seizure, coma, and fatality. CO is present in industrial processes such as vehicle emissions, boilers, blast furnaces, charcoal- kilns, garages and welding operations. The result of some studies of toxicity of $\mathrm{CO}$ in auditory system shows that it directly affects the cochlear function resulting NIHL. Alone it would not be ototoxic, but it may be when present with noise. Moreover, CO in cigarette components can reduce oxygen levels in cochlea and result 
in vasoconstriction, increased blood flow, reduced oxygen transport and oxyhemoglobin dissociation problems. Noise exposure also induces cochlear hypoxia, causing injury or interacting with the mechanisms of NIHL. Thus, chronic hypoxia caused by smoking can contribute to Hearing loss, particularly in the basal region of cochlea. Research suggests that smoking associated with the noise exposure induces Temporary Threshold Shift (TTS) and this effect is attributed more to $\mathrm{CO}$ than to Nicotine [3]. Noise levels during various operations in steel plants are high within the range of 84-120 dBA and thus the workers in steel industry are at risk of NIHL. Noise cannot only cause hearing impairment (at long term exposures of over 90 decibels), (Graph 2) but it also acts as a causal factor for stress and raises systolic blood pressure [4]. Therefore, the aim of the present study is to examine the Synergistic effect of Carbon-monoxide, Noise, Smoking and Hypertension on Hearing of Steel Industry workers. Hence council can be done for workers to use ear protection devices, provide guidelines before joining and organizing hearing conservation program.

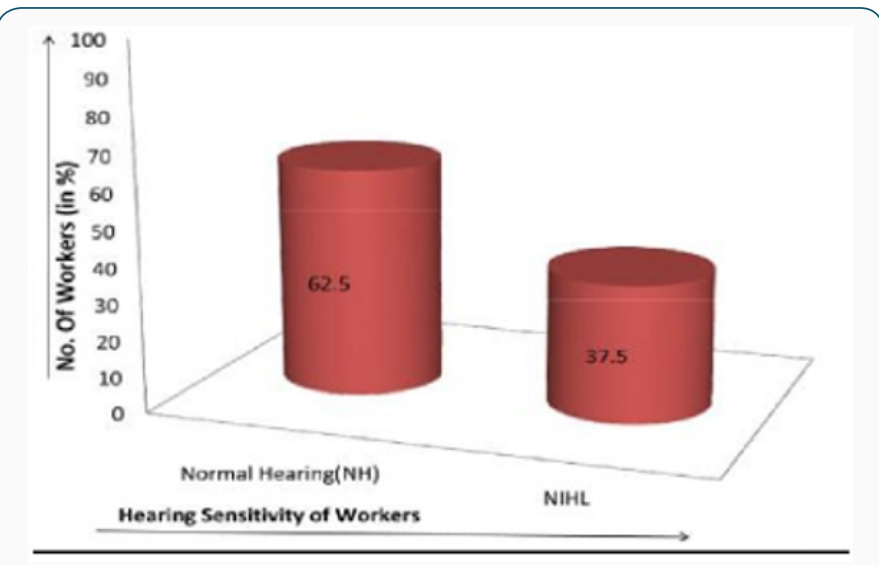

Graph 1: Depicts the number of workers having normal hearing and NHL.

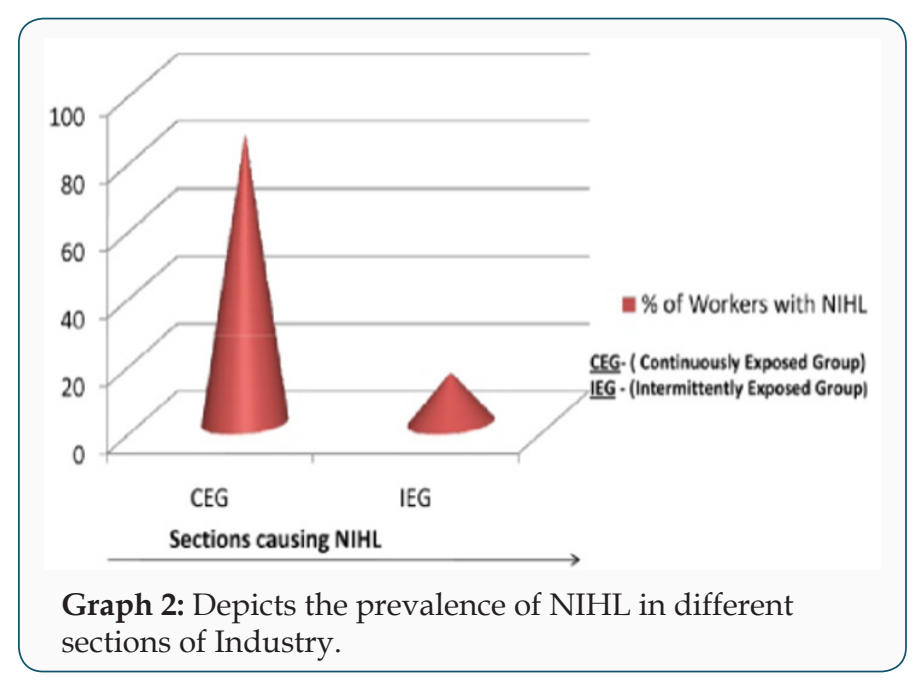

\section{Method}

72 male steel Industry workers were participated in the study. Written permission was obtained from the competent authority of the factory and cleared the study protocol. For analysis and internal comparison of production units such as Steel Melting Section
(SMS), Rolling Mill Section (RMS), and Power plant were taken together as Continuously Exposed Group (CEG), as workers were exposed to working environment continuously during the working hours. Administration Division (AD) consisting of stores, finance, purchase, medical etc. were taken as Intermittently Exposed Group (IEG) as workers visit the manufacturing units intermittently. The factory works continuously round the clock in three shifts of eight hours each. Posting of worker in particular section was of permanent nature. The shifts of workers were changed on rotation every week. Protective devices were available for workers in all sections. All the workers who participated in this study were examined in the factory occupational health center for medical checkup \& audiometry tests and biological concentration of $\mathrm{CO}$ in blood verified by laboratory examination of Carboxyhemoglobin ( $\mathrm{COHb}$ ). Each worker was interviewed and examined. Information from employees with respect to noise problems was collected in a proforma designed for this purpose.

\section{Blood pressure measurement}

Blood pressure (BP) was measured in supine position by using BP-Digital monitor (OMRON-HEM7120). It measures the blood pressure and pulse-rate and shows the result digitally. Pressure (Max)-299mmHg.After a brief period of rest for 5 minutes interval, BP was measured in a quite private room in a sitting posture. The systolic and diastolic BP were recorded and the average of 3 readings was used for data analysis. Hypertension was defined according to the 7th report of JNC (Joint National Committee on prevention, detection, evaluation and treatment of high BP) as systolic BP $>140 \mathrm{mmHg}$ and Diastolic $\mathrm{BP}>90 \mathrm{mmHg}$.

\section{Carboxyhemoglobin (COHb)examination}

The blast furnace is the only equipment at the company that produces CO. The operation of the furnace consists of burning charcoal, which generates at an elevated temperature, causing the iron ore inside the oven to be smelted and taken out to be stored in a heated container or solidified into bars. So, 3 types of jobs were found to be exposed to $\mathrm{CO}$ and noise in the work environment. Thus, all other jobs analyzed were not exposed to $\mathrm{CO}$ and were considered as exposed to noise only. The $\mathrm{COHb}$ examination was conducted in clinical lab by collecting blood from the worker at the end of the work day. To form risk groups, the area studied were those with environmental exposure to $\mathrm{CO}$ and noise production (1,2 and 3) or only noise (Dispatch, assembling and loading).

\section{Determination of Noise level at workplace}

Actual noise levels have been measured and their maximum and minimum values are taken for 3 minutes and the average reading was recorded. These details are given in (Table 1). The microphone of a Bruel \& Kjaer-Type-2250 sound level meter (SLM) was used and measurements were made from $1 \mathrm{~m}$ of distance.

\section{Audiometric Assessment}

Out of 80 workers, 8 workers were excluded because they have conductive and/or Mixed Hearing loss in their audiogram. Pure tone 
audiometry was conducted in a sound treated room with ambient noise levels within permissible limits according to ANSI standards (ANSI S3.6-ISO389). Air conduction thresholds were determined using MADSEN ITERA II audiometer with TDH 39 earphones and B-71 for Bone conduction. Air conduction thresholds were determined at octave and mid-octave frequencies from $250 \mathrm{~Hz}$ to 8 $\mathrm{KHz}$, Bone conduction at frequencies from 250 to $4 \mathrm{KHz}$ by using the modified Hughson Westlake procedure. The workers were tested at the starting of work shifts to minimize Temporary Threshold Shifts (TTS) effects. The tests were conducted for workers who are continuously exposed to noise and CO and only Noise (working in grinding sections) and for control group employees in Administration department having minimal occupational noise exposure. The workers tested were divided into 4 age groups: 20+30, 30+-40, 40+-50 and 50+-60years (Graph 3).

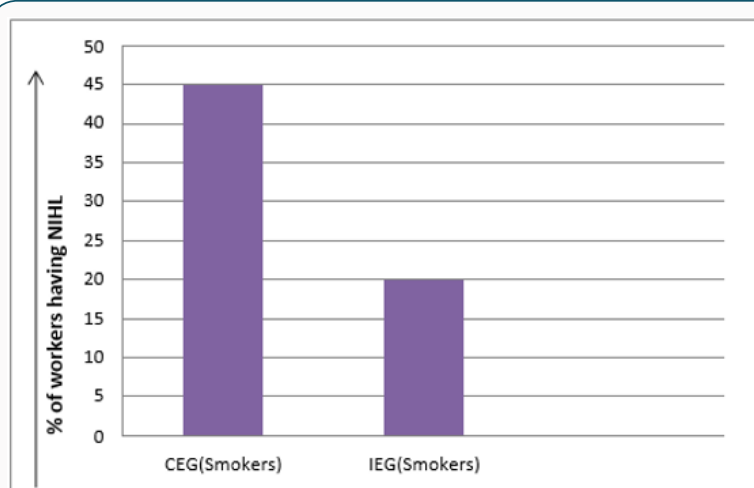

Prevalence of Hearing impairment in CEG workers (Smokers) and IEG(Smokers).

Graph 3: Depicts the prevalence of Hearing impairment in CEG workers (Smokers) and IEG(Smokers).

\section{Hearing Impairment Criteria:}

The hearing impairment criteria and classification suggested by (NIOSH, 1990). This helps to take corrective measures in the early stages of hearing loss. Based on hearing threshold level; the degrees of hearing loss are classified as below [5].

a) Normal hearing ( 0 to $25 \mathrm{~dB}$ ): At this level hearing is within normal limits.

b) Mild hearing loss (26 to $40 \mathrm{~dB}$ ): At this level, patients feel difficulty in suppressing background noise. Patients within this degree of loss may not hear soft speech.

c) Moderate hearing loss (41 to $55 \mathrm{~dB}$ ): Patients with this degree of loss have trouble hearing some conversational speech.

d) Moderate severe hearing loss (56 to $70 \mathrm{~dB}$ ): With this degree of loss patients do not hear most conversational level speech.

e) Speech hearing loss (71 to $90 \mathrm{~dB}$ ): Severe hearing loss may affect voice quality. f) Profound hearing loss (>90 dB): with profound hearing loss (deafness), speech and language deteriorate.

The dip or notch at $4 \mathrm{KHz}$ or $6 \mathrm{KHz}$ is a symptom of noise induced hearing loss.

\section{Statistical Analysis}

Data from completed questionnaire were entered in Microsoft excel spread sheets. Descriptive statistics were obtained by calculating the means of scores obtained by the subjects [6]. One way analysis of variance (ANOVA) and Student's t test was performed considering a significance level of $5 \%(p=0.05)$.

\section{Results}

Table 1 Depicts section wise distribution of noise level. It is observed that noise level was more than permissible limit in SMS, RMS, MBF and Power plant sections. Hearing impairment and Hypertension was found to be significantly more in these areas.

Table 1: Distribution of noise levels in different sections.

\begin{tabular}{|c|c|c|}
\hline Sections & Noise level (in dB) & Average Reading \\
\hline $\begin{array}{c}\text { Rolling Mill Section } \\
\text { (RMS) }\end{array}$ & $85-120$ & 102 \\
\hline $\begin{array}{c}\text { Steel Melting Sections } \\
\text { (SMS) }\end{array}$ & $80-102$ & 92 \\
\hline Blast furnaces & $80-108$ & 95 \\
\hline Power plant & $79-103$ & 99 \\
\hline Machine Shop (MS) & $86-97$ & 90 \\
\hline $\begin{array}{c}\text { Administrative } \\
\text { Department (AD) }\end{array}$ & $46-52$ & 49 \\
\hline
\end{tabular}

Table 2 Shows the age composition of the subjects working in the steel factory. Out of 72 participants 62 employees are working in manufacturing units exposed to noise and 10 employees were selected from administration stores, finance, medical etc. as control group who visit manufacturing section intermittently.

Table 2: Age composition of workers.

\begin{tabular}{|c|c|c|}
\hline Age (in years) & Number of persons & Percentage (\%) \\
\hline $21-30$ & 9 & 12.5 \\
\hline $31-40$ & 24 & 33.33 \\
\hline $41-50$ & 20 & 27.77 \\
\hline$>51$ & 19 & 26.38 \\
\hline Total & 72 & 100 \\
\hline
\end{tabular}

\section{Audiometric test reports}

The test reports of Audiometry for 72 employees both from study and control group studied in detail in present study. Table 3 Gives audiometric test reports for 72 employees indicating Hearing impairment of workers among Continuously Exposed Group (CEG) and Intermittently Exposed Group (IEG) workers. The degrees of hearing loss are classified into 6 groups as Normal, Mild, Moderate, Moderately severe, Speech hearing loss, and Profound hearing loss. It is found that nearly $62.5 \%$ of workers have normal hearing and 
about $37.5 \%$ of workers have Mild to Severe hearing loss. There are no cases of Speech hearing loss and profound hearing loss assessed during audiometric task. Indicates Hearing Impairment among workers in CEG is (31.94\%) which is much more than the hearing impairment that is (5.55\%) among IEG workers which indicates a positive relationship between noise exposure and Hearing Impairment.

Table 3: Audiometric results: Section wise HI details among Exposed and Control group Employees.

\begin{tabular}{|c|c|c|c|c|c|c|c|c|}
\hline \multicolumn{7}{|c|}{ Workers Exposed to Noise and CO } & \multicolumn{2}{|c|}{ Workers exposed to Only Noise } \\
\hline S. No & $\begin{array}{c}\text { Hearing } \\
\text { Level (in dB) }\end{array}$ & $\begin{array}{c}\text { Degrees of } \\
\text { HL }\end{array}$ & MBF & SMS & RMS & $\begin{array}{l}\text { Power } \\
\text { Plant }\end{array}$ & $\begin{array}{c}\text { Administration } \\
\text { Department }\end{array}$ & Total \\
\hline 1 & $0-25$ & Normal & 15 & 16 & 5 & 3 & 6 & 45 \\
\hline 2 & $26-40$ & Mild & 7 & 3 & 3 & 1 & 3 & 17 \\
\hline 3 & $41-55$ & Moderate & 3 & 1 & 1 & 1 & 1 & 7 \\
\hline 4 & $56-70$ & $\begin{array}{l}\text { Moderately } \\
\text { Severe }\end{array}$ & 1 & 1 & 1 & & & 3 \\
\hline 5 & $71-90$ & Severe & - & - & - & - & - & - \\
\hline 6 & $>90$ & Profound & - & - & - & - & - & - \\
\hline
\end{tabular}

a. SMS-Steel Making Shop.

b. RMS-Rolling Mill Division.

c. MBF- Mini Blast Furnaces.

d. Power Plant.

e. Administrative Department- Stores, Finance, Security, Medical etc.

Table 4 Shows age wise distribution of workers and association between hearing impairment and duration of exposure. As the age group increases, the workers are more experienced and their exposure to noise is long. Hearing impairment was found very high i.e. $66 \%$ among workers in the age group of $31-40$ whereas, Hearing impairment was found very less i.e., $29.6 \%$ in the age

group of 21-30. This clearly indicates that prevalence of hearing impairment was directly associated with duration of exposure. Table 5 Shows section-wise distribution of workers and association between hypertension and duration of exposure. It was observed that prevalence of hypertension was more among CEG as compared to IEG.

Table 4: Association between Age group \& Hearing Impairment.

\begin{tabular}{|c|c|c|c|c|c|c|c|}
\hline & \multicolumn{3}{|c|}{ CEG (Continuously Exposed Group) } & \multicolumn{3}{c|}{ IEG (Intermittently Exposed Group) } \\
\hline Age Group & Normal & Mild & Moderate & Severe & Normal & Mild & Moderate \\
\hline $21-30$ & 1 & 2 & 3 & 2 & - & - \\
\hline $31-30$ & 2 & 12 & 3 & 1 & - & 2 & - \\
\hline $41-50$ & 4 & - & - & - & - & - \\
\hline$<50$ & 2 & - & - & - & 6 & - & - \\
\hline & 9 & 14 & 6 & 3 & 6 & 2 & 1 \\
\hline
\end{tabular}

Data in cells represent number of subjects with hearing impairment Figures in parenthesis show percentage of " $\mathrm{n}$ "

Table 5: Section wise association between Age group \& Hypertension.

\begin{tabular}{|c|c|c|c|c|c|c|c|}
\hline & \multicolumn{3}{|c|}{ CEG (Continuously Exposed Group) } & \multicolumn{3}{c|}{ IEG (Intermittently Exposed Group) } \\
\hline Age Group & Normal & Mild & Moderate & Severe & Normal & Mild & Moderate \\
\hline $21-30$ & 1 & 2 & 3 & 2 & - & - \\
\hline $31-30$ & 2 & 12 & 3 & 1 & - & 2 & - \\
\hline $41-50$ & 4 & - & - & - & - & - \\
\hline$<50$ & 2 & - & - & - & 6 & - & - \\
\hline & 9 & 14 & 6 & 3 & 6 & 2 & 1 \\
\hline
\end{tabular}

SMS (Steel making shop) RMS (Rolling mill division) MBFs (Mini Blast Furnaces)

Technical Services- Civil, Power plant, Quality assurance department, Utility etc. Administration Department - Stores, Finance, security, Medical etc. So, CEG workers are more prone to Hearing Impairment. 
Table 6 Shows association between Hearing Impairment and Hypertension. It was observed that out of 27 workers with hearing impairment 21 workers (29.16\%) have hypertension and out of 45 workers with normal hearing $9(12.5 \%)$ workers have hypertension. This clearly indicates there is a positive association between hearing impairment and hypertension. Table 7 Shows association between level of sound and noise relative health problems like hypertension and hearing loss. It was observed that hypertension and hearing loss were more common in CEG group having high levels of noise and CO i.e. Blast furnaces, SMS, RMS, Power plant as compared to Administration section.

Table 6: Association between Hearing Impairment \& Hypertension.

\begin{tabular}{|c|c|c|c|}
\hline $\begin{array}{c}\text { Hearing } \\
\text { Impairment }\end{array}$ & Hypertensive & $\begin{array}{c}\text { Non- } \\
\text { Hypertensive }\end{array}$ & Total \\
\hline Present & $21(29.16 \%)$ & $6(8.33 \%)$ & 27 \\
\hline Absent & $9(12.5 \%)$ & $36(50 \%)$ & 45 \\
\hline & 30 & 42 & 72 \\
\hline
\end{tabular}

Table 7: Association between level of sound and noise induced hypertension \&Hearing impairment in each section.

\begin{tabular}{|c|c|c|c|}
\hline Section & Noise Level & $\begin{array}{c}\text { Number of } \\
\text { Person with } \\
\text { Hypertension }\end{array}$ & $\begin{array}{c}\text { Number of } \\
\text { Person with } \\
\text { Hearing } \\
\text { Impairment }\end{array}$ \\
\hline RMS & 102 & $7(23.33)$ & $8(29.62)$ \\
\hline SMS & 92 & $16(53.33)$ & $12(44.44)$ \\
\hline MBF & 95 & $4(13.33)$ & $4(14.81)$ \\
\hline Power Plant & 99 & $2(6.66)$ & $2(7.40)$ \\
\hline $\begin{array}{c}\text { Administrative } \\
\text { Department }\end{array}$ & 49 & $1(3.330)$ & $1(3.70)$ \\
\hline
\end{tabular}

(Figures in parenthesis denote percentage).

Table 8 Shows prevalence of Hearing Impairment in CEG \& Smoking and CEG only workers which shows positive relation between Hearing Impairment and $\mathrm{CO}$ exposure (Smoking) i.e. $30.64 \%$.

Table 8: Prevalence of Hearing Impairment in CEG \& Smoking and CEG workers only.

\begin{tabular}{|c|c|c|}
\hline $\begin{array}{c}\text { Hearing } \\
\text { Impairment }\end{array}$ & CEG \& Smoking & CEG only \\
\hline 27 & 19 & 4 \\
\hline
\end{tabular}

a) Value of $\% \mathrm{COHb}>2.26=$ Indicates that worker may be a regular smoker and /or Industrial CO concentration in his blood.

b) Value of \% $\mathrm{COHb} 1.13-1.70=$ Indicates that worker may be light smoker or has intermediate exposure of industrial CO.

c) Value of \% $\mathrm{COHb} 0.28-1.14=$ Indicates that worker has less than $1 \%$ CO in his blood and is due to the air quality around him in the industry.
Occupational noise is a widespread risk factor with a strong evidence base linking it to important health outcome that is hearing loss and hypertension [7]. It was found that Occupational Noise Induced Hearing Loss was most frequent among all occupational diseases. The prevalence rate of NIHL as per Central Labor Institute study is $15.2 \%$. In our study the prevalence rate of HL was $37.5 \%$. This may be due to high noise generation equipment and other environmental factors in the plant. In the present study the data related CO exposure and smoking were collected and found to be more prevalent to the hearing impairment. Nevertheless, the results of the present study indicate that hearing loss are significantly associated with duration of exposure of noise [8]. Both Noise induced health problems (Hypertension and Noise impairment) were common in CEG workers as compared to IEG workers.

\section{Discussion}

The noise levels in the (CEG) section are more than PEL (Permissible Exposure Limits)-8hrs, TWA (Time Weighted Average)-90dBA specified in the state regulations (OSHA, 2002). Both CO concentration and noise level were above the tolerance level according to regulatory norms of Ministry of labour and employment (1946). Among 72 workers (62.5\%) of workers had normal hearing whereas (37.5\%) had significant Noise Induced Hearing Loss [9]. The loss was seen in CEG (85.14\%) as compared to IEG (14.81\%) among the Hearing Impaired persons, as well as worsening of hearing thresholds at 3,4 and $6 \mathrm{kHz}$ indicating the chronic smoking enhance the effects of both $\mathrm{CO}$ and noise on the auditory system along with hypertension and rest were normal. Smokers had worse thresholds compared to their non-smoking peers $(p=0.009)$. There were significant differences between hearing thresholds and:

i. Smoking $(\mathrm{p}=0.009)$.

ii. Age $(\mathrm{p}=0.003)$.

iii. Noise level $(\mathrm{p}=0.05)$.

iv. Hypertension $(\mathrm{p}=0.05)$.

v. $\quad C O(p=0.009)$.

In all significant differences observed, there was a worsening of the audiometric results when: a) participants were smokers, b) participants were over 40 years old, c, d) when participants were exposed to noise when the noise level was higher than $85 \mathrm{dBA}$ which increase Hypertension, e) $\mathrm{CO}$ when \%COHb 1.13-1.70.

\section{Summary and Conclusion}

Age, time of exposure, type of exposure, level of noise, and smoking habit significantly influenced the auditory threshold of the participants. Smoking enhanced the effects of both $\mathrm{CO}$ and noise on the auditory system resulting in noise induced hearing loss in the steel industry. 


\section{Clinical Significance}

The present study determines the need of hearing check-up in every 6 months (OSHA,2002) in the steel industries along with the medical intervention in the cases of ear infections. Compulsion for using ear protection devices and decreasing the working hours for limiting the exposure of higher intensities and CO toxicity which in result can help to reduce hypertension. Providing ear health guidelines to the workers before joining and organizing hearing conservation programmers.

\section{References}

1. Elert Glenn (2016) The Nature of Sound. The Physics Hypertextbook, physics.info Retrieved p. 6-20.

2. Narlawar UW, Surjuse BG, Thakre SS (2006) Hypertension and hearing impairment in workers of iron and steel industry. Indian Journal of Physiology and Pharmacology 50(1): 60-66.

3. ASHA: American Speech-Language-Hearing Association [Internet]. The Audiologist's Role in Occupational Hearing Conservation and Hearing Loss Prevention Programs.
4. Lacerda A, Leroux T, Gagné JP (2005) The combined effect of noise and carbon monoxide on hearing thresholds of exposed workers. The Journal of the Acoustic Society of America 117(4): 2481.

5. NIOSH (1990) A practical guide to effective hearing conservation programs in the workplace. Cincinnati, Ohio: National Institute for Occupational Safety and Health. (DHHS (NIOSH) publication no. 90120).

6. Nelson DI, Nelson RY, Concha Barrientos M, Marilyn Fingerhut (2005) The global burden of occupational noise-induced hearing loss. Am J Ind Med 48(6): 446-458.

7. (2002) The Occupational Safety and Health Administration.

8. Talbott E, Helmkamo J, Matthews K, Kuller L, Cottington E, et al. (1985) Occupational noise exposure. Noise induced hearing loss and the epidemiology of high blood pressure. Am J Epidemiol 121(4): 505-514.

9. Wendy Pallant (2001) Deafness information sources and organizations concerning deafness. Levels of hearing loss.
This work is licensed under Creative Commons Attribution 4.0 License

To Submit Your Article Click Here:

Submit Article
DOI: $10.32474 /$ SJO.2018.01.000106

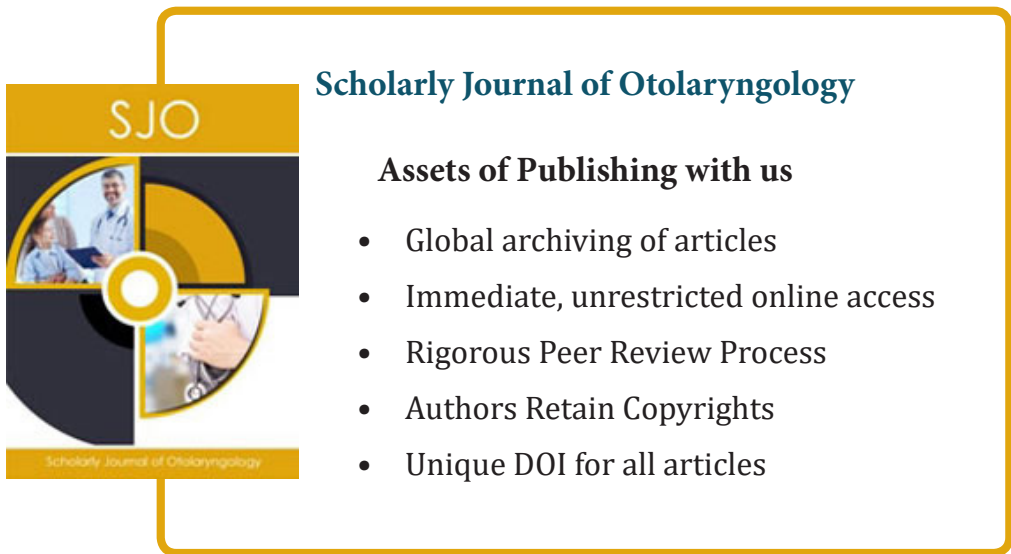

